\title{
TRATAMENTO DE ÁGUAS DE REFRIGERAÇÃO COM PERÓXIDO DE HIDROGÊNIO
}

\section{Fernando Antonio Serrapio Peres}

Divisão de Corrosão e Degradação, Instituto Nacional de Tecnologia, Av. Venezuela, 82, 20081-312 Rio de Janeiro - RJ, Brasil

\section{Luiz Alberto Cesar Teixeira*}

Departamento de Ciência dos Materiais e Metalurgia, Pontifícia Universidade Católica do Rio de Janeiro, Rua Marquês de São Vicente, 225, 22453-900 Rio de Janeiro -RJ/ Peróxidos do Brasil Ltda (grupo Solvay)

\section{Lídia Yokoyama e Juacyara Carbonelli Campos}

Departamento de Processos Inorgânicos, Escola de Química, Universidade Federal do Rio de Janeiro, Ilha do Fundão, Bloco E, 91949-900 Rio de Janeiro - RJ, Brasil

\section{Marco Antônio Lemos Miguel}

Departamento de Microbiologia Médica, Instituto de Microbiologia Prof. Paulo de Góes, Universidade Federal do Rio de Janeiro, Ilha do Fundão, CCS, Bloco I, 21944-970 Rio de Janeiro - RJ, Brasil

Recebido em 9/7/07; aceito em 15/2/08; publicado na web em 3/10/08

TREATMENT OF COOLING WATER WITH HYDROGEN PEROXIDE. Hydrogen peroxide and chlorine are compared as possible disinfectants for water-cooling circuits. To this purpose, samples taken from the cooling system of a steel making plant were treated (at $25^{\circ} \mathrm{C}$ and $\mathrm{pH}$ values of 5.5 and 8.5 ) with varying amounts of the two oxidizing agents $(0.0 \mathrm{mg} / \mathrm{L}, 2.0 \mathrm{mg} / \mathrm{L}$ and $6.0 \mathrm{mg} / \mathrm{L}$ ). The results were evaluated through bacterial counting and measurement of corrosion rates upon AISI1020 carbon steel coupons. Bacterial removal and corrosion effects proved to be similar and satisfactory for both reagents.

Keywords: cooling water; corrosion; biocide.

\section{INTRODUÇÃO}

Os microrganismos existentes nos sistemas de resfriamento de água industrial podem afetar de modo adverso a eficiência de operação nestes sistemas, seja pela quantidade, por seus produtos metabólicos ou pela formação de depósitos. ${ }^{1}$

Como resultado da atividade microbiológica nas águas de resfriamento, ocorre o acúmulo de limo bacteriano (biofilme) o que com o decorrer do tempo pode causar problemas de corrosão, obstrução de fluxos e diminuição da eficiência de troca térmica nos equipamentos. ${ }^{1}$

Dentre as técnicas aplicadas para prevenção e remoção do biofilme, a mais comum é a adição de substâncias biocidas capazes de eliminar e/ou inibir a reprodução de microrganismos nas águas de resfriamento. Os biocidas são compostos químicos que atuam de diversas formas, inibindo o crescimento e a atividade metabólica microbiana. ${ }^{2}$

Os biocidas podem atuar sobre os microrganismos de diferentes modos. Alguns modificam a permeabilidade da parede celular, alterando processos vitais que permitem a sua reprodução. Outros reagem irreversivelmente com enzimas do microrganismo, interferindo em todo o seu metabolismo, até provocar a sua morte. ${ }^{3,4}$

A maioria das indústrias utiliza o cloro como biocida no tratamento de águas de resfriamento, tanto na forma de cloro gás solubilizado $\left(\mathrm{Cl}_{2}\right)$ como na forma líquida, através da adição do hipoclorito de sódio $(\mathrm{NaClO})$. O cloro mostra-se extremamente eficaz na redução da contaminação microbiana em águas de resfriamento. Sua ação biocida está baseada na formação do ácido hipocloroso, resultante da adição de cloro à água, de acordo com as reações 1 e 2:5,6

$\mathrm{Cl}_{2(\mathrm{~g})}+\mathrm{H}_{2} \mathrm{O}_{(\text {(aq) }} \leftrightarrow \mathrm{HCl}_{(\mathrm{aq})}+\mathrm{HClO}_{(\text {(aq) }}$

$\mathrm{NaClO}_{(\mathrm{aq})}+\mathrm{H}_{2} \mathrm{O}_{(\mathrm{aq})} \leftrightarrow \mathrm{HClO}_{(\mathrm{aq})}+\mathrm{NaOH}_{(\mathrm{aq})}$

*e-mail: teixeira@dcmm.puc-rio.br
$\mathrm{O}$ ácido hipocloroso formado, dependendo do $\mathrm{pH}$, dissocia-se gerando $\mathrm{H}^{+}$e íon hipoclorito $\mathrm{ClO}^{-}$. O processo de cloração deve ser efetuado numa faixa de $\mathrm{pH}$ onde predomine o ácido hipocloroso. $\mathrm{O}$ íon hipoclorito também possui ação biocida, porém com poder muito menor. Logo, à medida que o $\mathrm{pH}$ da água aumenta, o poder do cloro de oxidar e desinfetar diminui. A Figura $1^{7}$ ilustra a distribuição destas espécies em função do $\mathrm{pH}$.

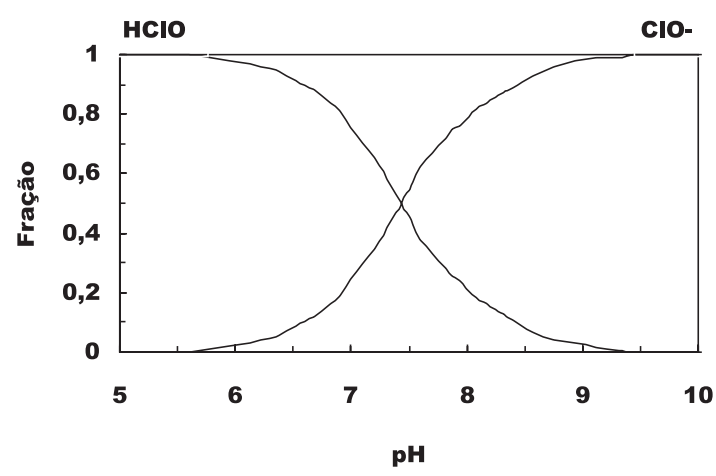

Figura 1. Diagrama de distribuição das espécies de cloro dissolvida em água em função do $\mathrm{pH}$, a $20^{\circ} \mathrm{C}^{7}$

O cloro apresenta a desvantagem de gerar subprodutos que podem diminuir a sua eficiência no combate aos microrganismos e que podem ser tóxicos ao corpo d'água que irá receber as descargas do sistema de resfriamento, tais como as cloroaminas e substâncias organocloradas. Além disso, o cloro é um composto oxidante e tende a provocar a incidência de processos corrosivos nos sistemas de resfriamento. ${ }^{8}$

O peróxido de hidrogênio é um produto muito utilizado no trata- 
mento de águas e efluentes industriais, apresentando uma reconhecida eficiência como bactericida e algicida. Porém, ainda é muito pouco utilizado isoladamente como biocida no tratamento de águas de resfriamento. Como vantagens, apresenta um menor custo em relação aos biocidas clorados e o fato de se decompor formando produtos inócuos na água. A sua aplicação é mais simples e mais segura quando comparada ao cloro, podendo ser aplicado diretamente na água através de bombas dosadoras. Por ser um forte oxidante, também causa corrosão de materiais.

Em meio aquoso, o peróxido de hidrogênio decompõe-se gradualmente liberando moléculas de oxigênio e água, de acordo com a reação 3 :

$$
2 \mathrm{H}_{2} \mathrm{O}_{2(\mathrm{aq})} \rightarrow \mathrm{O}_{2(\mathrm{~g})}+2 \mathrm{H}_{2} \mathrm{O}_{(\mathrm{aq})}
$$

A primeira etapa da pesquisa teve como objetivo comparar o desempenho do cloro e do peróxido de hidrogênio como biocida em diferentes valores de $\mathrm{pH}$ e em diferentes dosagens. Na segunda parte da pesquisa, foram estudadas as taxas de corrosão causadas pelo cloro e pelo peróxido de hidrogênio em superfícies de aço carbono AISI 1020, nas mesmas concentrações e valores de $\mathrm{pH}$ adotados na primeira parte da pesquisa.

\section{PARTE EXPERIMENTAL}

Os experimentos foram realizados com amostra de água de uma torre de resfriamento de indústria siderúrgica. Os ensaios foram conduzidos para avaliar os efeitos biocida e corrosivo do peróxido de hidrogênio e do cloro, sendo o do cloro através da adição de hipoclorito de sódio.

O efeito biocida foi acompanhado pela análise bacteriológica e o corrosivo, através da perda de massa de cupons de aço carbono AISI1020.

\section{Avaliação bacteriológica}

Os experimentos de contagem bacteriana foram realizados com o objetivo de examinar a carga microbiana nas amostras de água sem adição de biocidas e quando tratadas com cloro e peróxido de hidrogênio.

A avaliação microbiológica foi feita através do método Heterotrofic Plate Count, descrito por Cresceri. ${ }^{9}$

Procedeu-se à contagem bacteriana, adicionando-se uma alíquota da água a ser analisada em placas de Petri contendo o meio de cultura APC (Agar Padrão de Contagem). As amostras da água de resfriamento foram diluídas de $10^{-1}$ a $10^{-5} \mathrm{~mL}$ em água peptonada e inoculadas em placas de Petri contendo o meio de cultura. Após esta etapa, as placas foram incubadas em estufa bacteriológica durante 48 h a $37^{\circ} \mathrm{C}$.

A contagem de bactérias foi realizada após o período de incubação, contando-se o número de unidades formadoras de colônia (UFC) em cada placa de Petri. Ao final da contagem, multiplica-se o valor encontrado de unidades formadoras de colônias pelo inverso da diluição correspondente. $\mathrm{O}$ valor final foi obtido calculando-se a média de todas as contagens fornecidas em cada diluição.

As amostras de água de resfriamento foram dosadas com concentrações de 2,0 e 6,0 mg/L de cloro e peróxido de hidrogênio. As concentrações dos biocidas eram controladas através de medidas em um fotômetro Merck (Nova 60). O pH foi controlado após a adição dos biocidas, através de um potenciômetro, para valores de 5,5 e 8,5. O tempo total de ação dos biocidas nas amostras foi de $5 \mathrm{~h}$, tempo de contato que simula a duração de um ciclo de resfriamento típico em torres industriais. Durante o ensaio, a decomposição do cloro e do peróxido de hidrogênio foi monitorada realizando-se medidas das concentrações em intervalos de 30 min e quando necessário, repondo as dosagens dos biocidas para os valores inicialmente aplicados.

\section{Ensaio de corrosão}

A avaliação do efeito corrosivo do cloro e do peróxido de hidrogênio foi realizada através de ensaios de imersão de cupons metálicos de aço carbono AISI1020 (área de $26,2 \mathrm{~cm}^{2}$ ) em água destilada contendo dosagens de 2,0 e 6,0 mg/L dos biocidas em valores de pH 5,5 e 8,5. A taxa de corrosão também foi medida na água sem a adição dos biocidas. Os cupons metálicos foram preparados de acordo com os procedimentos descritos em NACE ${ }^{10}$ para testes estáticos de corrosão em temperaturas abaixo de $93{ }^{\circ} \mathrm{C}$. Os cupons foram previamente polidos com lixa de granulometria 120 mesh, com o objetivo de retirar depósitos aderidos à sua superfície. Após o procedimento de limpeza realizado através da imersão em álcool isopropílico e sucessivas lavagens com água desmineralizada e acetona, os cupons foram secados em estufa a $115^{\circ} \mathrm{C}$, durante aproximadamente $15 \mathrm{~min}$. Terminado o processo de limpeza, os cupons foram armazenados em dessecador até o momento de uso.

As experiências foram conduzidas em recipientes contendo $4 \mathrm{~L}$ de água destilada dosada com os biocidas. A escolha da água destilada foi feita em função de sua pureza, de modo a evitar a interferência de outros compostos dissolvidos no processo de corrosão. Todos os ensaios foram realizados em temperatura ambiente $\left(25 \pm 1^{\circ} \mathrm{C}\right)$ e em triplicata.

Antes de serem expostos à solução contendo biocida, os cupons foram pesados ao milésimo de grama em balança analítica (Marte, AL-500) e, só então, utilizados nos experimentos.

As concentrações de 2,0 e 6,0 mg/L de cloro ativo total e peróxido de hidrogênio foram controladas com o auxílio de um fotômetro (Merck, Nova 60). Imediatamente após a adição dos biocidas, o pH em cada recipiente foi ajustado, utilizando-se um potenciômetro (Micronal, B-375). O controle do $\mathrm{pH}$ foi mantido até o final em todas as experiências e acompanhado durante todo o experimento em cada recipiente.

Os cupons foram introduzidos nos recipientes plásticos e posicionados de modo a ficarem igualmente expostos ao volume de água no recipiente, como mostra a Figura 2.

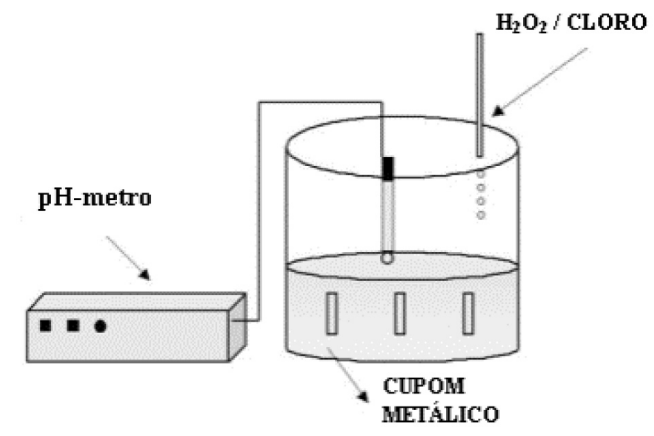

Figura 2. Aparato experimental para imersão de cupons metálicos em meio corrosivo

O período de exposição foi de 96 h e após 48 h de exposição, as concentrações de cloro ativo total e peróxido de hidrogênio foram medidas. Uma vez que estes compostos sofrem decomposição ao longo do tempo, periodicamente, suas concentrações eram recompostas para os valores iniciais.

Passadas 96 h de exposição, os cupons foram retirados do recipiente e submetidos ao mesmo processo de limpeza da fase de preparação, visando remover os produtos de corrosão aderidos na 
superfície. Após a limpeza, foram secados em estufa e armazenados em dessecador para posterior pesagem e cálculo da perda de massa e taxa de corrosão.

Para o cálculo da taxa de corrosão foi verificada a perda de massa ocorrida durante o ensaio de corrosão, subtraindo-se da sua massa original a massa após o ensaio. Os cupons foram pesados em balança analítica com precisão de milésimo de grama e o cálculo foi efetuado de acordo com a Norma NACE TM 0193-2000, através da seguinte equação:

$\mathrm{CR}=87,6 \mathrm{~W} / \mathrm{dAt}$

onde: $\mathrm{CR}=$ Taxa de corrosão $(\mathrm{mm} / \mathrm{y}), \mathrm{W}=$ perda de massa $(\mathrm{mg}), \mathrm{d}$ = densidade do cupom de prova $\left(\mathrm{g} / \mathrm{cm}^{3}\right), \mathrm{A}=$ área exposta do cupom de prova $\left(\mathrm{cm}^{2}\right), \mathrm{t}=$ tempo de exposição $(\mathrm{h})$. De acordo com NACE, ${ }^{10}$ a densidade do aço carbono AISI 1020 é $7,86 \mathrm{~g} / \mathrm{cm}^{3}$.

As taxas de corrosão foram obtidas em mmy (milímetros de penetração por ano), unidade que indica penetração e profundidade do ataque corrosivo. A taxa de corrosão em mmy foi convertida em mdd (miligramas por decímetro quadrado de área exposta por dia), através da equação mdd = mmy.d/0,036, em decorrência dessa unidade ser a mais utilizada no meio industrial.

Para cada dosagem aplicada do biocida, calculou-se a perda de massa média nos cupons de prova e obteve-se, assim, a taxa de corrosão média em cada condição. Para cada valor médio da taxa de corrosão obtida, foi calculado o desvio padrão experimental, o qual é definido por Triola ${ }^{11}$ como sendo a medida da variação dos valores experimentais em relação à média e pode ser calculado pela seguinte equação:

$\mathrm{S}=\left[\Sigma(\mathrm{Xi}-\mathrm{Xm})^{2} / \mathrm{n}-1\right]^{1 / 2}$

onde $\mathrm{S}$ é o desvio padrão, Xi o valor experimental, $\mathrm{Xm}$ a média e $\mathrm{n}$ é o número de valores experimentais.

Para verificar a homogeneidade dos valores, foi calculado o coeficiente de variação de Pearson (CVP), que é a razão entre o desvio padrão e a média e fornece uma estimativa da dispersão e variabilidade dos dados. Quanto menor for o valor de CVP, maior será a homogeneidade dos valores obtidos. O CVP pode ser determinado pela equação $\mathrm{CVP}=\mathrm{S} / \mathrm{Xm} \times 100$

\section{RESULTADOS E DISCUSSÃO}

\section{Avaliação bacteriológica}

Os resultados obtidos mostraram que o peróxido de hidrogênio, face ao erro experimental, apresentou uma eficiência biocida comparável à do cloro nos dois valores de $\mathrm{pH}$ testados, como se pode observar na Tabela 1.

Não existe, até o presente momento, nenhuma legislação ou norma internacionalmente aceita que estabeleça um padrão de qualidade para águas utilizadas em processos de resfriamento. Porém, alguns autores e empresas da área de tratamento de águas adotam critérios de qualidade a serem seguidos para evitar danos causados por corrosão, incrustações e crescimento microbiológico.
Normalmente adota-se como limite máximo de carga microbiana em águas de resfriamento a especificação microbiológica de 1,0 x $10^{4} \mathrm{UFC} / \mathrm{mL}$, sendo este valor um consenso entre a maioria dos autores da área.

Pelos resultados obtidos, pode-se observar que com a adição de ambos os biocidas foi possível reduzir a carga bacteriana na água para um valor menor do que a especificação microbiológica adotada pelas indústrias.

Em relação ao cloro, foi observada uma maior redução da população bacteriana em $\mathrm{pH} 5,5$, reduzindo de $10^{5}$ para $10^{2} \mathrm{UFC} / \mathrm{mL}$, enquanto que em $\mathrm{pH} 8,5$, a redução foi de $10^{5}$ para $10^{3} \mathrm{UFC} / \mathrm{mL}$. O melhor desempenho do cloro em $\mathrm{pH}$ 5,5 deve-se ao fato de que, nesta condição, a espécie de cloro ativo predominante é a forma de ácido hipocloroso $(\mathrm{HClO})$, o qual possui um poder biocida maior que o íon hipoclorito $\left(\mathrm{ClO}^{-}\right)$, que predomina em $\mathrm{pH} 8,5$.

Os resultados do peróxido de hidrogênio sugerem que a sua ação biocida é pouco influenciada pelo $\mathrm{pH}$. Na faixa de $\mathrm{pH}$ estudada, a redução foi de $10^{5}$ para $10^{3} \mathrm{UFC} / \mathrm{mL}$ na população bacteriana, a uma dosagem de $2 \mathrm{mg} / \mathrm{L}$ do peróxido de hidrogênio. Entretanto, foi verificada uma redução maior na concentração de $6,0 \mathrm{mg} / \mathrm{L}$ (de $10^{5}$ para $\left.10^{2} \mathrm{UFC} / \mathrm{mL}\right)$.

O peróxido de hidrogênio mostra uma atividade eficaz frente a amplo espectro de microrganismos, porém a presença das enzimas catalase e peroxidase ou de outras enzimas no ambiente intracelular pode aumentar a tolerância do microorganismo na presença deste agente em baixas concentrações, como as utilizadas nos experimentos. Sua atividade pode ser inativada na presença destas enzimas, o que resulta na degradação do peróxido de hidrogênio em água e oxigênio. ${ }^{12}$

Impurezas presentes na água podem interferir na atividade do peróxido de hidrogênio. Vários fatores influenciam a decomposição do peróxido de hidrogênio, tais como temperatura, $\mathrm{pH}$ e a presença de impurezas na água, como traços de cobre, manganês e ferro. Normalmente observa-se uma maior tendência de decomposição em valores de $\mathrm{pH}$ alcalino. ${ }^{13}$

Durante o período em que foi exposta à atmosfera industrial, a água ficou próxima a uma unidade de aciaria. Este processo normalmente gera emissões de material particulado na atmosfera da área industrial, contendo vários metais.

Alguns ensaios preliminares revelaram uma expressiva decomposição do peróxido de hidrogênio quando aplicado nas concentrações de 2,0 e 6,0 mg/L na amostra coletada. Aplicou-se o produto nas duas concentrações em duas amostras da água em pH neutro e após $1 \mathrm{~h}$ de ação, foi realizada uma medida da sua concentração na água. Este ensaio mostrou uma redução de $50 \%$ na concentração inicial de $2,0 \mathrm{mg} / \mathrm{L}$ e uma redução de $62 \%$ sobre a concentração inicial de $6,0 \mathrm{mg} / \mathrm{L}$. Em experiências repetidas dosando cloro nas mesmas concentrações, foram observadas reduções menores que $10 \%$. Em água destilada, supostamente isenta de impurezas metálicas, não foi observada decomposição do peróxido de hidrogênio e do cloro no período de $1 \mathrm{~h}$.

A presença de traços de alguns destes metais na água pode ter contribuído para a menor eficiência do peróxido de hidrogênio quando comparado ao cloro nos experimentos realizados.

Tabela 1. Resultados dos ensaios de contagem microbiológica em função do biocida e pH em tempo de contato de $5 \mathrm{~h}$

\begin{tabular}{lcccc}
\hline $\begin{array}{l}\text { Dosagem do biocida } \\
(\mathrm{mg} / \mathrm{L})\end{array}$ & $\begin{array}{c}\text { Contagem bacteriana } \\
(\mathrm{UFC} / \mathrm{mL}) \mathrm{H}_{2} \mathrm{O}_{2}, \mathrm{pH} 8,5\end{array}$ & $\begin{array}{c}\text { Contagem bacteriana } \\
(\mathrm{UFC} / \mathrm{mL}) \mathrm{H}_{2} \mathrm{O}_{2}, \mathrm{pH} \mathrm{5,5}\end{array}$ & $\begin{array}{c}\text { Contagem bacteriana } \\
(\mathrm{UFC} / \mathrm{mL}) \mathrm{cloro}, \mathrm{pH} 8,5\end{array}$ & $\begin{array}{c}\text { Contagem bacteriana } \\
(\mathrm{UFC} / \mathrm{mL}) \mathrm{cloro}, \mathrm{pH} 5,5\end{array}$ \\
\hline 0 & $8,0 \times 10^{5}$ & $3,4 \times 10^{5}$ & $8,0 \times 10^{5}$ & $3,4 \times 10^{5}$ \\
2 & $6,2 \times 10^{3}$ & $1,1 \times 10^{3}$ & $3,3 \times 10^{3}$ & $3,8 \times 10^{2}$ \\
6 & $1,4 \times 10^{3}$ & $7,6 \times 10^{2}$ & $2,2 \times 10^{3}$ & $1,1 \times 10^{2}$ \\
\hline
\end{tabular}


Tabela 2. Resultados dos ensaios de corrosão com peróxido de hidrogênio

\begin{tabular}{|c|c|c|c|c|c|c|}
\hline $\begin{array}{l}\text { Dosagem do bio- } \\
\text { cida }(\mathrm{mg} / \mathrm{L})\end{array}$ & $\begin{array}{c}\text { Taxa de corrosão } \\
\text { média em pH=5,5 } \\
(\mathrm{mdd})\end{array}$ & $\begin{array}{c}\text { Desvio padrão em } \\
\mathrm{pH}=5,5 \text { (mmd) }\end{array}$ & $\begin{array}{c}\text { CVP (\%) em } \\
\mathrm{pH}=5,5\end{array}$ & $\begin{array}{c}\text { Taxa de corrosão } \\
\text { média em } \mathrm{pH}=8,5 \\
(\mathrm{mdd})\end{array}$ & $\begin{array}{c}\text { Desvio padrão em } \\
\mathrm{pH}=8,5 \text { (mmd) }\end{array}$ & $\begin{array}{c}\operatorname{CVP}(\%) \mathrm{em} \\
\mathrm{pH}=8,5\end{array}$ \\
\hline 0 & 31 & 4,6 & 15 & 31 & 1,7 & 5,5 \\
\hline 2 & 36 & 1,6 & 4,4 & 36 & 3,5 & 9,7 \\
\hline 6 & 41 & 5,0 & 12 & 40 & 1,1 & 2,7 \\
\hline
\end{tabular}

Tabela 3. Resultados dos ensaios de corrosão com cloro (hipoclorito de sódio)

\begin{tabular}{|c|c|c|c|c|c|c|}
\hline $\begin{array}{l}\text { Dosagem do bio- } \\
\text { cida }(\mathrm{mg} / \mathrm{L})\end{array}$ & $\begin{array}{c}\text { Taxa de corrosão } \\
\text { média em } \mathrm{pH}=5,5 \\
(\mathrm{mdd})\end{array}$ & $\begin{array}{c}\text { Desvio padrão em } \\
\mathrm{pH}=5,5 \text { (mmd) }\end{array}$ & $\begin{array}{c}\text { CVP (\%) em } \\
\mathrm{pH}=5,5\end{array}$ & $\begin{array}{c}\text { Taxa de corrosão } \\
\text { média em } \mathrm{pH}=8,5 \\
(\mathrm{mdd})\end{array}$ & $\begin{array}{c}\text { Desvio padrão em } \\
\mathrm{pH}=8,5 \text { (mmd) }\end{array}$ & $\begin{array}{c}\text { CVP }(\%) \text { em } \\
\mathrm{pH}=8,5\end{array}$ \\
\hline 0 & 31 & 4,6 & 15 & 31 & 1,7 & 5,5 \\
\hline 2 & 34 & 1,6 & 4,4 & 31 & 1,2 & 3,9 \\
\hline 6 & 39 & 4,0 & 10 & 35 & 1,6 & 4,5 \\
\hline
\end{tabular}

\section{Ensaios de corrosão}

As Tabelas 2 e 3 apresentam os resultados dos ensaios de corrosão usando peróxido de hidrogênio e cloro, respectivamente.

Os resultados obtidos sugerem que os efeitos corrosivos do cloro e do peróxido de hidrogênio no material testado são muito próximos, não permitindo afirmar qual é o produto mais corrosivo.

A aplicação de cloro (hipoclorito de sódio) gerou uma corrosão ligeiramente menor em $\mathrm{pH}$ 8,5, possivelmente pela predominância do íon hipoclorito nesta condição, que é um oxidante mais fraco do que o ácido hipocloroso, que predomina em pH 5,5.

O mecanismo de ataque corrosivo do cloro no ferro pode ser observado nas seguintes reações 4 e 5 :

$$
\begin{aligned}
& \mathrm{HClO}_{(\mathrm{aq})}+\mathrm{H}_{(\mathrm{aq})}^{+}+2 \mathrm{e} \rightarrow \mathrm{Cl}_{(\mathrm{aq})}^{-}+\mathrm{H}_{2} \mathrm{O}_{(\mathrm{aq})} \\
& \mathrm{ClO}_{(\mathrm{aq})}^{-}+2 \mathrm{H}^{+}{ }_{(\mathrm{aq})}+2 \mathrm{e} \rightarrow \mathrm{Cl}_{(\mathrm{aq})}^{-}+\mathrm{H}_{2} \mathrm{O}_{(\mathrm{aq})}
\end{aligned}
$$

$\mathrm{O}$ íon cloreto gerado corrói o ferro gerando $\mathrm{FeCl}_{2}$. Este sal se hidrolisa, gerando ácido clorídrico, que oxidará o ferro, como se pode observar pelas reações 6 e 7 :

$$
\begin{aligned}
& \mathrm{FeCl}_{2(\mathrm{~s})}+2 \mathrm{H}_{2} \mathrm{O}_{(\mathrm{aq})} \rightarrow 2 \mathrm{HCl}_{(\mathrm{aq})}+\mathrm{Fe}(\mathrm{OH})_{2(\mathrm{~s})} \\
& \mathrm{Fe}_{(\mathrm{s})}+2 \mathrm{HCl}_{(\mathrm{aq})} \rightarrow 2 \mathrm{FeCl}_{2(\mathrm{aq})}+\mathrm{H}_{2(\mathrm{~g})}
\end{aligned}
$$

O processo corrosivo prossegue com a hidrólise do $\mathrm{FeCl}_{2}$, gerando mais $\mathrm{HCl}$, que atacará o ferro gerando corrosão por "pites" em sua superfície.

O efeito corrosivo do peróxido de hidrogênio não foi influenciado pelo $\mathrm{pH}$, obtendo-se as mesmas taxas de corrosão nas duas condições. O mecanismo de corrosão do peróxido de hidrogênio segue pelas reações 8 e 9 :

$$
\mathrm{H}_{2} \mathrm{O}_{2(\mathrm{aq})}+2 \mathrm{H}_{(\mathrm{aq})}^{+}+2 \mathrm{e} \rightarrow 2 \mathrm{H}_{2} \mathrm{O}_{(\mathrm{aq})}
$$

$\mathrm{Fe}_{(\mathrm{s})}+2 \mathrm{H}_{2} \mathrm{O}_{2(\mathrm{aq})} \rightarrow \mathrm{Fe}(\mathrm{OH})_{2(\mathrm{~s})}$

Todos os ensaios de imersão foram realizados em meio aerado, sendo assim, deve-se levar em conta o efeito corrosivo do oxigênio no material estudado. Segundo Gentil, ${ }^{14}$ o oxigênio ataca o ferro formando uma camada de hidróxido ferroso $\left(\mathrm{Fe}(\mathrm{OH})_{2}\right)$, que sofre oxidação devido à presença do oxigênio no meio:

$$
\mathrm{Fe}(\mathrm{OH})_{2(\mathrm{~s})}+2 \mathrm{H}_{2} \mathrm{O}_{(\mathrm{aq})}+1 / 2 \mathrm{O}_{2(\mathrm{~g})} \rightarrow 2 \mathrm{Fe}(\mathrm{OH})_{3(\mathrm{~s})}
$$

A presença do depósito de $\mathrm{Fe}(\mathrm{OH})_{3}$, produto de corrosão, foi facilmente observada nos cupons de prova expostos à água com cloro, peróxido de hidrogênio e sem biocida, sendo caracterizada por um depósito de cor castanho escura, como pode ser visto na Figura 3.

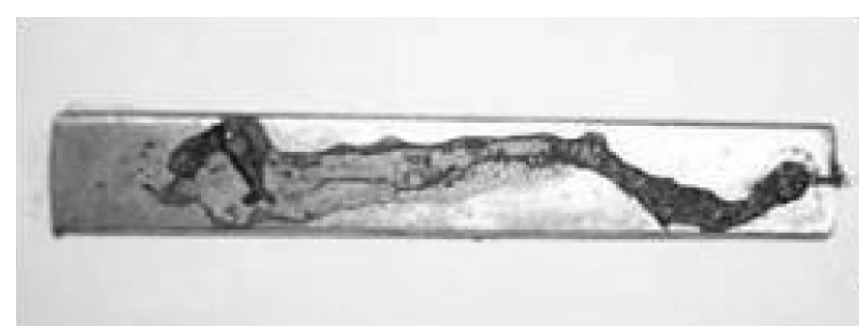

Figura 3. Depósito de $\mathrm{Fe}(\mathrm{OH})_{3}$ observado nos cupons, após ensaios com cloro e peróxido de hidrogênio

\section{CONCLUSÕES}

O peróxido de hidrogênio apresenta efeito biocida em água semelhante ao do cloro em pH igual a 8,5 com redução de dois ciclos logaritmicos na população bacteriana, e com redução de 3 ciclos em $\mathrm{pH}$ igual a 5,5.

Com relação à corrosividade sobre o aço carbono, o peróxido de hidrogênio apresentou uma ação corrosiva também comparável à do cloro, respectivamente, taxas de 41 contra 39 mdd em pH $=5,5$ e 40 contra $35 \mathrm{em} \mathrm{pH}=8,5$, valores esses referenciados a desvios padrão das medidas que se situaram entre 1,1 e 5,0. Cabe notar que as taxas de corrosão medidas foram bem abaixo da taxa limite recomendada pelos especialistas de 100 mdd.

As vantagens operacionais do uso do peróxido de hidrogênio sobre o cloro (ou hipoclorito) foram identificadas como sendo maior grau de segurança industrial com o uso do peróxido de hidrogênio; maior grau de qualidade ambiental nas purgas de água dos circuitos de refrigeração com o uso do peróxido de hidrogênio e, custos de processo competitivos frente ao cloro, ou inferiores frente ao hipoclorito. 


\section{AGRADECIMENTOS}

Ao CNPq e à Peróxidos do Brasil, pelo apoio financeiro; a toda equipe do Laboratório de Microbiologia de Alimentos da UFRJ, pela colaboração na análise microbiológica.

\section{REFERÊNCIAS}

1. Tanji, Y.; Nishihara, T.; Miyanaka, K.; Biochem. Eng. J. 2007, 35, 81.

2. Melo, L. F.; Bott, T. R.; Experimental Thermal and Fluid Science 1997, 14,375 .

3. Denyer, S. P.; Stewart, G. S. A. B.; International Biodeterioration and Biodegration 1998, 41, 261.

4. Gonçalves, N. J.; Dissertação de Mestrado, Universidade Federal do Rio de Janeiro, Brasil, 2002.

5. Dantas, E.; Tratamento de Água de Refrigeração e Caldeiras, 1ª. ed., Ed. Ecolab: Rio de Janeiro, 1988.
6. Tashikawa, M.; Tezuka, M.; Morita, M.; Isogai, K.; Okada, S.; Water Res. 2005, 39, 4126.

7. Medusa-Chemical Equilibrium Software (2.0), KTH - Institutionen för Kemi.

8. Chelossi, E.; Faimali, M.; Sci. Total Environ. 2006, 356, 1.

9. Clesceri, L. S.; Greenberg, A. E.; Eaton, A. D.; Standard Methods for Examination of Water and Wastewater, $20^{\text {th }}$ ed., American Public Health Association: Washington, D.C.,1998.

10. NACE International Corrosion Society; NACE TM 0193-2000: Laboratory Corrosion Testing of Metals in Static Chemical Cleaning Solutions at Temperatures Below $93^{\circ} \mathrm{C}$, NACE International: Houston, 2000.

11. Triola, M. F.; Introdução à Estatística, 1ª . ed., LTC: Rio de Janeiro, 1998.

12. Donnell, G. Mc.; Russell, A. D.; Clin. Microbiol. Reviews 1998, 12, 147.

13. http://h2o2.com/intro/faq.html, acessada em Junho 2005.

14. Gentil, V. ; Corrosão, $4^{\mathrm{a}}$. ed., LTC Editora: Rio de Janeiro, 2003. 